\title{
The diagnosis and management of atrial fibrillation in the horse
}

This article was published in the following Dove Press journal:

Veterinary Medicine: Research and Reports

26 February 2015

Number of times this article has been viewed

\section{Kimberly J McGurrin}

Health Sciences Centre, Ontario Veterinary College, University of Guelph, Guelph, ON, Canada
Correspondence: M Kimberly J McGurrin Health Sciences Centre, Ontario

Veterinary College, University of Guelph, 50 Stone Road East, ON NIG 2WI, Canada

Tel +l 2269245854

Email mcgurrin@uoguelph.ca
Abstract: Atrial fibrillation is the most common performance-limiting arrhythmia in the horse. Detailed cardiovascular evaluation will help guide prognosis and treatment. Many affected horses have lone atrial fibrillation (no predisposing cardiac abnormalities). These horses have a good prognosis for return to performance if sinus rhythm can be restored. The main therapeutic option continues to be quinidine, which has been used for over 60 years. Transvenous electrical cardioversion has proven to be a successful alternative. Other therapeutic options are being explored, but are currently limited.

Keywords: atrial fibrillation, quinidine, cardioversion, ECG, arrhythmia, TVEC

\section{Introduction}

Atrial fibrillation (AF), the most common performance limiting arrhythmia in the horse, was first documented by electrocardiogram (ECG) in 1911. ${ }^{1}$ In a study of over 2,500 horses, the incidence was reported to be as high as $2.5 \% .^{2} \mathrm{~A}$ large proportion of these horses were at an abattoir, and poor performance might have influenced inclusion in the study. A lower incidence might therefore be considered. ${ }^{3}$ Predisposing factors, associated and underlying disease, and clinical signs vary. ${ }^{3-7}$ A majority of horses have lone AF; the arrhythmia is the only cardiovascular abnormality., ${ }^{5,-10}$ These horses are usually treated to allow them to return to full performance. ${ }^{9-11}$ Treatment options have historically been limited to quinidine salts. ${ }^{3,9-16}$ Recently, other therapeutic options have been investigated. ${ }^{17-29}$

\section{Atrial fibrillation - the arrhythmia}

In AF, the normal coordinated electrical and contractile mechanisms within the atria are lost. Instead, within the atria, multiple portions of the myocardium are in different stages of electrical and mechanical activity. The preponderant theories involve fronts of electrical activity passing through the myocardium interacting with each other and with structural barriers (such as the vena cava). ${ }^{30-32}$ Atrial electrical and mechanical properties have been shown to remodel rapidly in response to AF, stabilizing the arrhythmia. ${ }^{32,33}$ With a larger atrium, more wavelets can develop and be sustained, facilitating the presence of AF. High vagal tone has also been shown in other species to cause variability in the action-potential duration, ${ }^{34}$ propagating wavelets and maintaining the arrhythmia: the fronts of activity interact with portions of atrial myocardium at different stages of susceptibility. ${ }^{35}$ Horses have large atria and high vagal input, creating an ideal environment for the sustenance of AF should it be initiated. 
The atria contribute to cardiac output, with about $20 \%$ of ventricular stroke volume being contributed by the atrium. ${ }^{36,37}$ With the loss of coordinated atrial activity in AF, the atria fail to contract and the ventricular rhythm becomes irregular. The result is inconsistent ventricular filling. ${ }^{38}$ During short cycles, there is insufficient time for the ventricle to fill, resulting in decreased stroke volume for those beats. Many of the impulses that reach the atrioventricular node are blocked, due to an absolute or relative refractory period. In the horse, there is also a high vagal tone providing additional block to the $\mathrm{AF}$ impulses. ${ }^{39}$ The resting heart rate is rarely increased, provided there is no underlying or associated disease (lone AF). Because of the normal ventricular rate, cardiac output at rest is not markedly affected. At exercise, the vagal input is lost, and the atrial contribution becomes more important as the demands on cardiac output approach maximum. Exaggerated heart-rate responses in $\mathrm{AF}$ at exercise are common.

While a number of classification systems have been proposed for $\mathrm{AF}^{40}{ }^{40}$ the system that is most applicable to the horse is to classify based on duration/timing pattern. In this system, AF is considered as paroxysmal, persistent, recurrent, or permanent. Paroxysmal AF is defined as an arrhythmia episode that terminates spontaneously. In persistent AF, the episodes of AF last longer than 7 days. ${ }^{40}$ In either situation, if the arrhythmia is detected more than once, it is recurrent. The arrhythmia is classified as permanent when it either does not respond to treatment or when treatment is not attempted in long-standing persistent $\mathrm{AF}^{40}$

AF may also be classified based on the presence of associated or underlying conditions. If there is underlying structural cardiac disease or associated metabolic disturbances, then the $\mathrm{AF}$ is considered secondary. Lone AF is considered when no associated abnormalities are determined on detailed cardiovascular examination. ${ }^{40}$

While in humans thromboembolism and associated complications, such as stroke, are a considerable risk during $\mathrm{AF}$ and immediately following cardioversion, ${ }^{40}$ there is no apparent risk in horses, and there are no reported incidences in horses. The use of anticoagulants is therefore not indicated as part of the management of $\mathrm{AF}$ in horses.

A presumptive diagnosis may be made on auscultation. The heart rhythm is irregularly irregular, typically with a few more rapid beats interspersed with longer pauses of variable length. The fourth heart sound (atrial contraction) is absent. A definitive diagnosis requires an ECG. The ECG pattern is one of irregularly spaced ventricular complexes, absent $\mathrm{P}$ waves and the presence of $\mathrm{F}$ (fibrillation) waves (Figures 1 and 2). The $\mathrm{F}$ waves on the surface ECG are a summation along the plane of the ECG lead of the wavelets of electrical activity within the atria.

\section{Clinical signs of AF in the horse}

The presenting signs of a horse with AF are variable. ${ }^{3-16}$ Some horses might present with overt clinical signs that range from subtle through dramatic poor performance to, in rare instances, collapse. ${ }^{3,10}$ Exercise-induced pulmonary hemorrhage has been associated with AF. In some cases, AF might almost be considered an incidental finding. It has been noted at routine examination and at examination for purchase. In such cases, horses have been reported as performing to expectation.

In many horses, once $\mathrm{AF}$ is initiated, the rhythm remains until it is treated, and is termed persistent AF. If the rhythm is not responsive to any form of treatment, then the term "permanent AF" is used. In some horses, AF occurs intermittently, and ceases within 48 hours without intervention. ${ }^{8}$ Paroxysmal AF is often a frustrating condition to manage in the horse. ${ }^{7,8}$ While there are some interventions that may aid in the initial restoration of sinus rhythm (SR), or might decrease the tendency for recurrence (correction of electrolyte abnormalities, anti-inflammatory medications), the recurrent nature tends to lead to inconsistent performance. The short durations of arrhythmia also present a challenge, and the diagnosis may be presumptive. Paroxysmal, persistent, or permanent AF may all be variants of lone AF (no detected

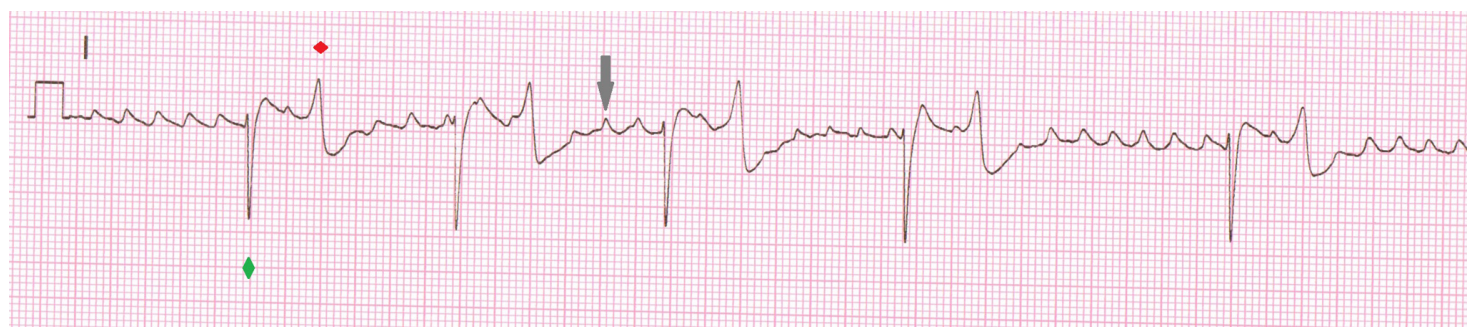

Figure I Electrocardiogram recorded from a horse in atrial fibrillation.

Notes: Note the irregularly spaced QRS complexes, the absence of a $\mathrm{P}$ wave, and the lack of a smooth baseline. The coarse undulations that are occurring throughout the recording are $\mathrm{F}$ (fibrillation) waves. The green diamond indicates a QRS complex, the red square a $\mathrm{T}$ wave, and the gray arrow is pointing to an $\mathrm{F}$ wave. 


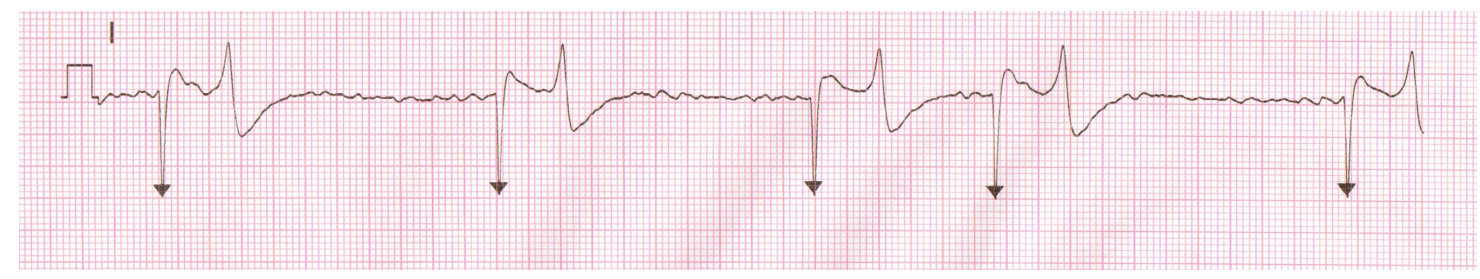

Figure 2 Electrocardiogram recorded from a horse in atrial fibrillation.

Notes: The QRS complexes, indicated by the black triangles, are irregularly spaced. In this recording, there are no $\mathrm{P}$ waves, and the $\mathrm{F}$ waves are fine.

cardiac disease) ${ }^{40}$ AF may also be present in horses with marked cardiac abnormalities, and in these horses is considered to be a secondary development, due to atrial dilatation. Some horses with secondary AF are limited more due to the primary condition than due to the AF.

The differences in clinical presentation for lone AF are considered to relate to the performance demands placed upon the horses. Horses that are working near maximal cardiovascular demands are more likely to show evidence of poor performance. Others are considered to be working within their reserve capacity.

\section{Diagnostic testing}

All horses that are suspected to have AF should have an ECG. This confirms the arrhythmia and rules out other rhythms that might sound similar. Sinus arrhythmia can also be irregularly irregular; however, it should disappear with light exercise, and the ECG will reveal sinus conduction (P present with every QRS, and smooth baseline). Second-degree atrioventricular block (Figure 3) should also disappear with exercise, and the overall conduction is SR (P present with every QRS, smooth baseline, P noted on its own in blocked cycles). The ECG also allows the ventricular complexes to be evaluated. The presence and frequency of abnormal ventricular complexes should be noted. If present, this is added stimulus to correct the $\mathrm{AF}$, and the horse is unsafe to leave in $\mathrm{AF}$, but the abnormal ventricular complexes might be due to aberrant conduction associated with $\mathrm{AF}^{41}$ and the horse may be able to resume performance upon treatment.

Echocardiography allows the evaluation of underlying and associated cardiac disease or conditions.
Underlying disease might be valvular insufficiency and chamber dilatation. Mild valvular insufficiency is common in the horse, and is generally not considered to be contributing to the $\mathrm{AF} .{ }^{10}$ Moderate-to-severe valvular insufficiency, especially if accompanied by atrial dilatation, is more worrisome, and is more likely to be contributory to development of AF. ${ }^{1-10}$ An associated condition would be chamber dysfunction; this is unlikely to have caused AF, but might be as a result. ${ }^{10} \mathrm{Left}$ ventricular functional indices may be reduced, and often these improve upon treatment. Moderate reductions would be added impetus to treat the horse, even if the horse was in a lower performance category.

If there is a consideration of not treating the horse, then an exercising ECG is advised. The heart-rate response to exercise should be monitored. Exercising ECGs in AF horses were first reported in 1976. ${ }^{11}$ An exaggerated response to exercise was noted. The horses had rapid increase in heart rates, and had an excessive heart rate for the level of exercise. ${ }^{11}$ The exercise test was repeated after the horses were cardioverted using quinidine. A $30 \%$ reduction in the heart rates for the level of exercise was noted once the horses were in SR. Altered atrioventricular nodal conduction has been proposed as a potential reason for increased heart-rate response during exercise. ${ }^{41}$ This study also suggested that horses in AF had increased abnormal ventricular complexes at exercise. ${ }^{41}$ From these results, there is good evidence to treat horses that are to be more intensively exercised. Horses with abnormal complexes at exercise should be considered for cardioversion, and safety would preclude intense exercise in the face of ventricular ectopics (Figure 4). The heart-rate response at exercise should also be evaluated. The horse should be

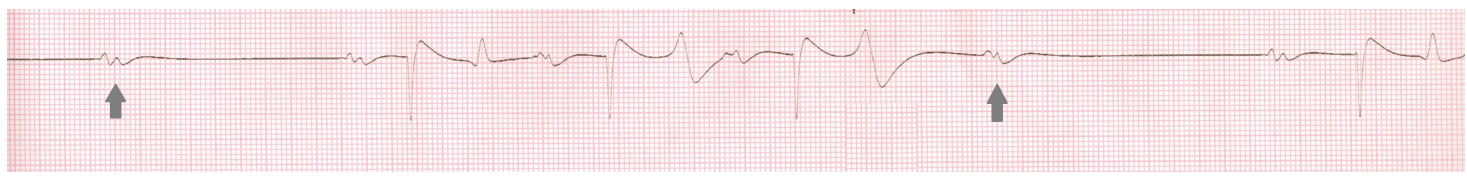

Figure 3 Electrocardiogram recorded from a horse with advanced second-degree atrioventricular block.

Notes: The QRS complexes in the middle of the strip are evenly spaced; however, there is a long gap before and after these. There are two $\mathrm{P}$ waves (gray arrows) that are not followed by QRS complexes; these are blocked cycles. The first one on the strip is following a previously blocked $\mathrm{P}$ wave. The gaps are of predictable length (gaps between $\mathrm{P}$ waves are the same, whether blocked at the atrioventricular node or not). 


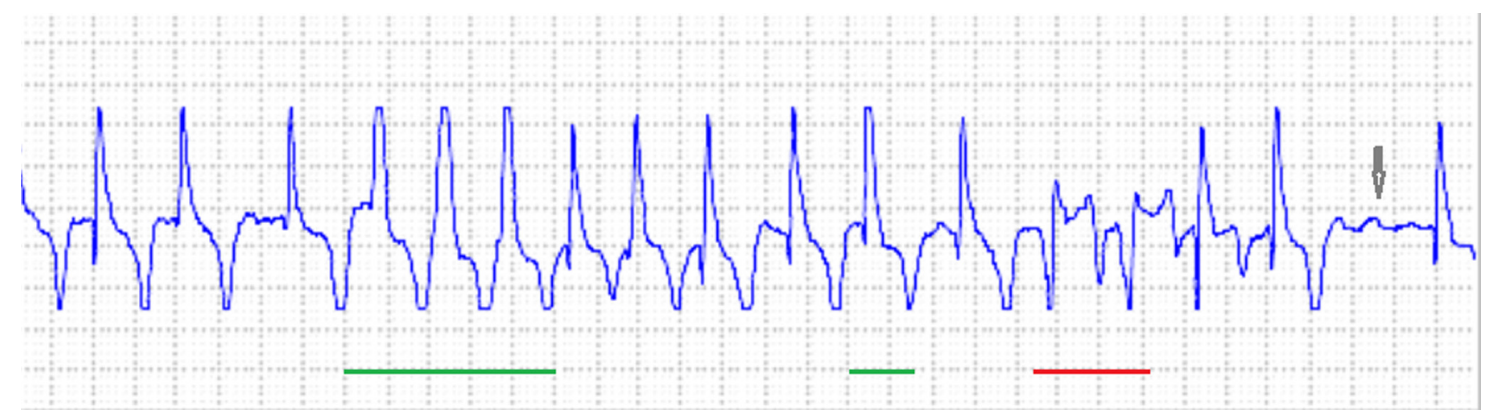

Figure 4 Holter electrocardiogram recording from a horse in atrial fibrillation.

Notes: In this recording, there is some artifact, and the electrocardiogram is cut off at the top and the bottom. The significant findings in this recording are the heart-rate response; the horse was standing in the stall. This is excessive heart-rate response to being fed. The instantaneous rate exceeds 150 bpm in the sinus beats mid-strip. The complexes that are underlined in green are widened and are considered to be ventricular ectopics. The complexes that are underlined in red have changed polarity as well as being widened, and are also considered to be ventricular ectopics. The arrow shows the " $f$ " waves.

worked to an appropriate level consistent with conditioning/ training at that time. Heart-rate responses during SR are generally related to speed/work. At submaximal effort, there is some variability due to fitness and excitement level. At heart rates over $150 \mathrm{bpm}$, the effects of excitation are minimal. ${ }^{42}$ The initial overshoot in rate at each upward transition is also well documented. The anticipated heart-rate responses in the normal horse (SR) are 90-120 bpm at the trot, 140-160 bpm at the canter, and 200-240 bpm at the gallop/near maximalmaximal effort. ${ }^{42}$ If the heart-rate response is greatly exaggerated for the level of work, then either cardioversion or cessation of work is indicated. ${ }^{43}$

\section{Treatment}

Treatment for AF in horses is aimed at restoring SR cardioversion. ${ }^{43}$ This may be through either pharmacological or nonpharmacological methods. Cardioversion is not considered during the first 48 hours of an AF episode, due to the possibility of spontaneous conversion to normal SR. ${ }^{43}$ Once this time period has passed, then cardioversion should be considered. Any horse that is to be used for intense athletic activity should be cardioverted. The prognosis for cardioversion should be considered; the presence of underlying cardiac disease will decrease prognosis both for response to treatment and maintenance of SR. Cardioversion, regardless of the method used, should only be performed where there is ability to perform continuous monitoring and 24-hour ECG capabilities. ${ }^{43}$

\section{Pharmacologic cardioversion}

Quinidine (a class IA antiarrhythmic: mostly sodium channel-blocking activity) has been and remains the pharmacologic option of choice. Detailed descriptions of the use of quinidine to treat AF in the horse have been published over the past 60 years. ${ }^{9-16}$ Generally, quinidine has been administered orally as quinidine sulfate, with success rates as high as $88 \%$ reported. ${ }^{10}$ Careful selection of candidates for treatment will influence success rates, and lower response rates should be anticipated if candidates are not ideal (very short duration, lone AF).

Oral administration consists of administration via stomach tube, due to the bitter taste and the propensity for oral irritation. ${ }^{9,10,16}$ An initial frequency of every 2 hours may be followed by every 6 hours if cardioversion is not achieved. ${ }^{10,16}$ This approach titrates and maintains therapeutic levels, which are fairly narrow. Ideally, quinidine levels are measured, with therapeutic levels being $2-5 \mu \mathrm{g} / \mathrm{L} .{ }^{10,16}$ With AF durations of less than 4 months, lone $\mathrm{AF}$ and resting heart rate of fewer than $60 \mathrm{bpm}$, the prognosis for cardioversion is good. ${ }^{10,16}$

Side effects ranging from mild depression and muzzle edema, through colic, diarrhea, decreased blood pressure, weakness, ataxia, and severe arrhythmias to collapse and death, have been reported. In one study, up to $75 \%$ of side effects or toxic responses were noted. ${ }^{10}$ Many side effects are dose-related, and can be reduced or avoided with appropriate measures. Horses undergoing quinidine therapy should be hospitalized and treated as intensive care patients. Continuous observation is required. Close behavioral and physical monitoring is essential. Prompt assessment of changes, such as noting mild depression, altered posture, or change in feces, might mitigate progression to more severe signs. Heart rates and ECGs should be monitored hourly at minimum, with ideally continuous ECG monitoring. Torsades de pointes, a potentially fatal wide polymorphic ventricular tachycardia, may be first seen as QRS widening. ${ }^{9,10}$ Frequent QRS measurements are essential. Increased heart-rate response and QRS widening are indicators to alter or stop treatment. Medication should be stopped if the heart rate exceeds $80 \mathrm{bpm}$ or if the QRS duration exceeds $120 \%$ of 
its baseline. ${ }^{10}$ Some centers monitor blood pressure with tail-cuff measurements.

Intravenous quinidine salts (mostly quinidine gluconate) have also been administered as a short continuous-rate infusion or as repeated doses over a short time period. ${ }^{15}$ This regimen is considered to have highest efficacy with recent-onset $\mathrm{AF}$ ( $<2$ months). An advantage to this method is the timing to peak levels, the titration is rapid, and levels decrease more rapidly than with oral administration (there is no more to be absorbed should an adverse response be observed). Price, formulations, and availability may be restrictive.

Other pharmacologic options have been investigated. Propafenone (a class IC antiarrhythmic), and sotalol (a class III antiarrhythmic) have not proven to have any clinical efficacy. ${ }^{21,28}$ Flecainide (a class IC antiarrhythmic) showed promise in short-duration (15 minutes) experimentally induced $\mathrm{AF}^{26}$ It has also been reported as effective orally in one clinical case (with some side effects: QRS prolongation, abdominal discomfort). ${ }^{27}$ It has not proved effective when used intravenously, and serious arrhythmias have been encountered..$^{29}$ Considerations of potential adverse effects should be weighed carefully prior to considering this medication.

Amiodarone (a class III antiarrhythmic), when administered intravenously, has been showed to have moderate efficacy. ${ }^{18,20}$ This medication is administered as a constantrate infusion following a loading dose. The medication has approximately $60 \%$ reported efficacy in cases of chronic AF. Side effects, including elevated liver indices and hind-limb weakness, necessitating removal of medication, were noted in $33 \%$ of horses in one study. ${ }^{18}$ Prolonged administration ( $>36$ hours) was associated with increased risk of severe diarrhea. ${ }^{20}$ The advice with this medication is therefore to limit the duration of administration. Amiodarone has also been used in association with electrical cardioversion to reduce risk of early recurrence of AF following that procedure in some cases. ${ }^{19,44,45}$

Digoxin is not used to convert AF to SR. It is used to control the ventricular rate in $\mathrm{AF}^{10,16}$ It is used in horses that are to remain in $\mathrm{AF}$ but that have a high heart rate (due to heart failure or an otherwise unusual ventricular rate response) to maintain heart rate at a more normal rate. It is also used in some horses that are undergoing pharmacologic treatment with quinidine. ${ }^{10,16}$ Some horses become tachycardic during treatment, but show no other adverse responses to quinidine; with the addition of digoxin, the heart-rate response is controlled and treatment can continue. As quinidine and digoxin compete for binding sites and transport proteins (risk of digoxin overdose) monitoring becomes particularly important, and measuring levels is ideal.

\section{Nonpharmacologic options}

Electrical cardioversion is often used in humans where restoration of SR is desired. Due to high AF recurrence, presence of underlying disease, and studies showing limited benefit to rhythm control, ventricular rate control is often performed in humans. ${ }^{33}$ The principles of electrical cardioversion are to deliver enough electrical energy to the atria, such that the sufficient myocardium becomes depolarized and the AF activity becomes interrupted. The signal from the sinus node can then become reestablished. The timing of the shock is important. The ventricle is affected by the electrical shock as well. If the shock is applied during ventricular repolarization (the $\mathrm{T}$ wave), ventricular arrhythmia and potentially ventricular fibrillation could result and be fatal..$^{43}$ The shock is therefore synchronized with the QRS.

Successful external electrical cardioversion has been reported in one horse. ${ }^{22}$ Routine application of this procedure could be challenging. Based on humans, the estimated energy required for transthoracic cardioversion is similar to that for ventricular fibrillation ( $4 \mathrm{~J} / \mathrm{kg}$ ); the energy requirements to externally cardiovert a horse could be high. Commercially available defibrillators deliver a maximum of $360 \mathrm{~J}$. There is one report of successful external cardioversion of $\mathrm{AF}$ in a horse. ${ }^{22}$ The procedure was attempted unsuccessfully in two horses. On the second attempt, in one $393 \mathrm{~kg}$ horse, cardioversion to SR was successful. The energy level was relatively low $(0.5 \mathrm{~J} / \mathrm{kg}){ }^{22}$ The energy level may have been influenced in part by the short duration of AF, and the horse was pretreated with quinidine. ${ }^{22}$ The careful electrode placement also likely had an influence. The electrodes need to be positioned over the atria. This requires that the horse be placed in dorsal recumbency, and that the electrodes be positioned on either side of the thorax. Patches were used in the published report, and ultrasound was used to guide electrode positioning. ${ }^{22}$

Transvenous electrical cardioversion (TVEC) involves the placement of catheter-mounted electrodes within or near the atria, and decreases energy requirements. The equipment and facility requirements are high. Various configurations of catheter designs have been used with success in the horse. ${ }^{19,23-25}$ An advantage to TVEC is that antiarrhythmic medications are not required; therefore, this option is a consideration for those animals in which these medications are not an option (did not work/adverse response). With TVEC, the electrodes are placed through a jugular vein and guided into the right 
atrium and left pulmonary artery. ${ }^{23,24}$ The horse is placed under general anesthesia.

Thoracic radiography is used to confirm electrode positioning once the horse is anesthetized. Electrode repositioning is performed if required. Biphasic electrical shocks are applied, with incremental increases in energy levels, until SR is restored or until a preset maximum energy level is reached. A sample protocol is that used at the Ontario Veterinary College, where the initial energy is $50 \mathrm{~J}$ and synchronized biphasic shocks are delivered every 2 minutes (50, 70, 100, $125,150,175,200,250,300 \mathrm{~J}$ ); the procedure is stopped at SR or at $300 \mathrm{~J}$, whichever happens first. ${ }^{23,24}$ The catheters are then removed. The horse is recovered from anesthesia.

In some cases, if the horse has a history of early recurrence of $\mathrm{AF}$, a number of atrial premature contractions are seen, or depending on the treating center or clinician, an antiarrhythmic medication may be administered to decrease the risk of early (within 24 hours) recurrence of AF. Many horses are not treated with additional medications. TVEC has efficacy as high as $98 \%$. Efficacy may be influenced by case selection or by technique, including electrode design and positioning. ${ }^{24,25,46}$ Breed, patient weight, and duration of AF were not shown to influence efficacy in two studies. ${ }^{24,46}$ Horses with AF have been reported as good candidates for anesthesia, and the anesthetic risks for the procedure are reported as comparable to other elective anesthetic

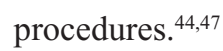

In humans, there are further options for the management of AF. Many patients may benefit from pulmonary vein ablation, as this is the source of the arrhythmia. ${ }^{48}$ Once the pulmonary veins are isolated and cardioversion performed, rhythm may remain normal. At this time, both because of level of knowledge and because of the size and anatomy of the horse, ablation is not a possibility in the horse.

Following any treatment, the duration of AF may impact the rest period. AF-induced remodeling, based upon other species and the small numbers of equine studies, is influenced by duration of $\mathrm{AF}^{28,45,49,50}$ Horses with $\mathrm{AF}$ of very short duration $(<1$ week) are likely to be able to return to work very quickly. There is evidence of persistence of functional changes lasting more than 8 weeks in horses that have been converted from chronic AF. ${ }^{50}$ These horses might therefore benefit from a more prolonged rest period.

\section{Prognosis}

AF has a good prognosis for return to full performance. If SR can be restored, the horse with lone AF is considered to be clinically normal. There is a low chance for recurrence, with reports of between $15 \%$ and $20 \%$. Recurrence rate is influenced by the treatment group; therefore, selection criteria for treatment will influence recurrence. Horses with longer duration of AF or associated cardiac disease will likely have higher recurrence rates. Based on low recurrence rates, continued antiarrhythmic medication following restoration of SR is not indicated. Early recurrence (within 24 hours) of AF has been noted in a few cases following TVEC. ${ }^{19,45}$ To minimize this, some cases have been treated with a short course of antiarrhythmics. Overall, the recurrence rates between horses treated with quinidine and TVEC are considered similar. ${ }^{10,19,23-25,43,45,46}$ There appears to be a higher risk for recurrence in warm-blood horses and in horses that had AF for longer duration prior to treatment. . $^{10,43,46}$ Slow return to exercise in the latter group may decrease risk of early recurrence due to AF-induced remodeling. ${ }^{45,49}$

Evaluation of the horse postcardioversion may help assess the prognosis, and guide the return to performance. Twenty-four-hour Holter recording may be used to evaluate for atrial arrhythmias. ${ }^{43}$ Persistent atrial ectopia should indicate that the horse requires further rest. Echocardiography to determine atrial function might be of value; however, unless the AF is recent, persistent dysfunction has been noted for several weeks. ${ }^{43,50}$ Evaluation of left ventricular function is however indicated, and could be performed within 48 hours of treatment. ${ }^{43}$ Ideally, the horse should be rested until all electrical and mechanical functions have returned to normal.

\section{Disclosure}

The author reports no conflicts of interest in this work.

\section{References}

1. Lewis T. Irregularity of the heart's action in horses and its relation to fibrillation of the auricles in experiment and to complete irregularity of the human heart. Heart. 1911;3:161.

2. Else RW, Holmes JR. Pathological changes in atrial fibrillation in the horse. Equine Vet J. 1971;3:56-64.

3. Deem DA, Fregin GF. Atrial fibrillation in horses - a review of 106 clinical cases, with consideration of prevalence, clinical signs, and prognosis. J Am Vet Med Assoc. 1982;180:261-265.

4. Donald DE, Elliot FJ. Auricular fibrillation in horses. Vet Rec. 1949;60:473.

5. Detweiler DK. Experimental and clinical observations on auricular fibrillation in horses. Proc Am Vet Med Assoc. 1952:119-129.

6. Amada A, Senta T, Kubo K, Oh-ishi S, Kiryu K. Atrial fibrillation in the horse: clinical and histopathological study of 2 cases. I. Clinical study. Exp Rep Equine Health Lab. 1974;5:1-69.

7. Holmes JR, Drake PG, Else RW. Atrial fibrillation in the horse. Equine Vet J. 1969;1:211-222.

8. Amada A, Kurita H. Five cases of paroxysmal atrial fibrillation in the racehorse. Exp Rep Equine Health Lab. 1975;12:89-100.

9. Morris DD, Fregin GF. Atrial fibrillation in horses: factors associated with response to quinidine sulfate in 77 clinical cases. Cornell Vet. 1982;72:339-349. 
10. Reef VB, Levitan CW, Spencer PA. Factors affecting prognosis and conversion in equine atrial fibrillation. J Vet Intern Med. 1988;2:1-6.

11. Deegen E, Buntenkötter S. Behaviour of the heart rate of horses with auricular fibrillation during exercise and after treatment. Equine Vet J. 1976;8:26-29.

12. Amada A, Senta T, Seno T. Quinidine therapy of equine auricular fibrillation. Exp Rep Equine Health Lab. 1965;3:133-143.

13. Glendinning SA. The use of quindine sulphate for the treatment of atrial fibrillation in twelve horses. Vet Rec. 1965;77:951.

14. Muir WW, McGuirk SM. Hemodynamics before and after conversion of atrial fibrillation to normal sinus rhythm in horses. $J$ Am Vet Med Assoc. 1984;8:965-970.

15. Muir WW 3rd, Reed SM, McGuirk SM. Treatment of atrial fibrillation in horses by intravenous administration of quinidine. J Am Vet Med Assoc. 1990;197:1607-1610.

16. Reef VB, Reimer JM, Spencer PA. Treatment of atrial fibrillation in horses: new perspectives. J Vet Intern Med. 1995;9:57-67.

17. De Clercq D, van Loon G, Baert K, et al. Intravenous amiodarone treatment in horses with chronic atrial fibrillation. Vet J. 2006;172: 129-134.

18. De Clercq D, van Loon G, Baert K, et al. Effects of an adapted intravenous amiodarone treatment protocol in horses with atrial fibrillation. Equine Vet J. 2007;39:344-349.

19. De Clercq D, van Loon G, Schauvliege S, et al. Transvenous electrical cardioversion of atrial fibrillation in six horses using custom made cardioversion catheters. Vet J. 2008;177:198-204.

20. De Clercq D, van Loon G, Tavernier R, Duchateau L, Deprez P. Atrial and ventricular electrical and contractile remodeling and reverse remodeling owing to short-term pacing-induced atrial fibrillation in horses $J$ Vet Intern Med. 2008;22:1353-1359.

21. De Clercq D, van Loon G, Tavernier R, Verbesselt R, Deprez P. Use of propafenone for conversion of chronic atrial fibrillation in horses. Am J Vet Res. 2009;70:223-227.

22. Frye MA, Selders CG, Mama KR, Wagner AE, Bright JM. Use of biphasic electrical cardioversion for treatment of idiopathic atrial fibrillation in two horses. J Am Vet Med Assoc. 2002;220:1039-1045.

23. McGurrin MK, Physick-Sheard PW, Kenney DG, et al. Transvenous electrical cardioversion in equine atrial fibrillation: technique and successful treatment of 3 horses. J Vet Intern Med. 2003;15:715-718.

24. McGurrin MK, Physick-Sheard PW, Kenney DG. How to perform transvenous electrical cardioversion in horses with atrial fibrillation. J Vet Cardiol. 2005;7:109-119.

25. McGurrin MK, Physick-Sheard PW, Kenney DG, Kerr C, Hanna WJ. Transvenous electrical cardioversion of equine atrial fibrillation: technical considerations. J Vet Intern Med. 2005;19:695-702.

26. Ohmura H, Nukada T, Mizuno Y, Yamaya Y, Nakayama T, Amada A. Safe and efficacious dosage of flecainide acetate for treating equine atrial fibrillation. J Vet Med Sci. 2000;62:711-715.

27. Risberg AI, McGuirk SM. Successful conversion of equine atrial fibrillation using oral flecainide. J Vet Intern Med. 2006;20:207-209.

28. van Loon G. Methods of treatment and new management techniques in horses with atrial fibrillation. In: Martin M, Boswood A. The Autumn Meeting of the Veterinary Cardiovascular Society. Ghent, Belgium: Ghent University; 2003:12-17.

29. van Loon G, Blissitt KJ, Keen JA, Young LE. Use of intravenous flecainide in horses with naturally occurring atrial fibrillation. Equine Vet J. 2004;36:609-614.

30. Allessie MA, Bonke FI, Schopman FJ. Circus movement in rabbit atrial muscle as a mechanism of tachycardia. III. The 'leading circle' concept: a new model of circus movement in cardiac tissue without the involvement of an anatomical obstacle. Circ Res. 1977;41:9-18.

31. Moe GK, Rheinboldt WC, Abildskov JA. A computer model of atrial fibrillation. Am Heart J. 1964;67:200-220.

32. Moe GK. A conceptual model of atrial fibrillation. J Electrocardiol. 1968;1:145-146.
33. Nattel S, Guasch E, Savelieva I, et al. Early management of atrial fibrillation to prevent cardiovascular complications. Eur Heart J. 2014;35: 1448-1456.

34. Loomis TA, Krop S. Auricular fibrillation induced and maintained in animals by acetylcholine or vagal stimulation. Circ Res. 1955;3: 390-396.

35. Wijffels MC, Kirchhof CJ, Dorland R, Allessie MA. Atrial fibrillation begets atrial fibrillation. A study in awake chronically instrumented goats. Circulation. 1995;92:1954-1968.

36. LindererT, Chatterjee K, Parmley WW, Sievers RE, Glantz SA, Tyberg JV. Influence of atrial systole on the Frank-Starling relation and the enddiastolic pressure-diameter relation of the left ventricle. Circulation. 1983;67:1045-1053.

37. Mitchell JH, Gupta DN, Payne RM. Influence of atrial systole on effective ventricular stroke volume. Circ Res. 1965;17:11-18.

38. Effat M, Schick EC, Martin DT, Gaasch WH. Effect of rhythm regularization on left ventricular contractility in patients with atrial fibrillation. Am J Cardiol. 2000;85:114-116.

39. Hamlin RL, Klepinger WL, Gilpin KW, Smith CR. Autonomic control of heart rate in the horse. Am J Physiol. 1972;222:976-978.

40. Fuster V, Rydén LE, Cannom DS, et al. ACC/AHA/ESC 2006 Guidelines for the Management of Patients with Atrial Fibrillation: a report of the American College of Cardiology/American Heart Association Task Force on Practice Guidelines and the European Society of Cardiology Committee for Practice Guidelines (Writing Committee to Revise the 2001 Guidelines for the Management of Patients with Atrial Fibrillation): developed in collaboration with the European Heart Rhythm Association and the Heart Rhythm Society. Circulation. 2006;114:e257-e354.

41. Verheyen T, Decloedt A, van der Vekens N, Sys S, De Clercq D, van Loon $\mathrm{G}$. Ventricular response during lungeing exercise in horses with lone atrial fibrillation. Equine Vet J. 2013;45:309-314.

42. Merlin D, Narkervis K. Equine Exercise Physiology. Oxford: Wiley; 2013.

43. ReefVB, Bonagura J, Buhl R, et al. Recommendations for management of equine athletes with cardiovascular abnormalities. JVet Intern Med. 2014;28:749-761

44. Schauvliege S, van Loon G, De Clercq D, Devisscher L, Deprez P, Gasthuys F. Cardiovascular responses to transvenous electrical cardioversion of atrial fibrillation in anaesthetized horses. Vet Anaesth Analg. 2009;36:341-351.

45. Decloedt A, Verheyen T, Van Der Vekens N, Sys S, De Clercq D, van Loon G. Long-term follow-up of atrial function after cardioversion of atrial fibrillation in horses. Vet J. 2013;197:583-588.

46. Preiss EE, Kenney DG, McGurrin MK, Physick-Sheard PW. Influence of electrode position on cardioversion energy requirements during transvenous electrical cardioversion in horses. Am J Vet Res. 2011;72: 1193-1203.

47. Bellei MH, Kerr C, McGurrin MK, Kenney DG, Physick-Sheard P. Management and complications of anesthesia for transvenous electrical cardioversion of atrial fibrillation in horses: 62 cases (2002-2006). J Am Vet Med Assoc. 2007;231:1225-1230.

48. Manlucu J, Brancato S, Lane C, Kazemian P, Michaud GF. Contemporary approaches to persistent atrial fibrillation. Expert Rev Cardiovasc Ther. 2012;10:1421-1435.

49. Nattel S, Burstein B, Dobrev D. Atrial remodeling and atrial fibrillation: mechanisms and implications. Circ Arrhythm Electrophysiol. 2008;1: $62-73$.

50. Schwarzwald CC, Schober KE, Bonagura JD. Echocardiographic evidence of left atrial mechanical dysfunction after conversion of atrial fibrillation tosinus rhythm in 5 horses. $J$ Vet Intern Med. 2007;21: $820-827$. 


\section{Publish your work in this journal}

Veterinary Medicine: Research and Reports is an international, Visit http://www.dovepress.com/testimonials.php to read real quotes peer-reviewed, open access journal publishing original research, case reports, editorials, reviews and commentaries on all areas of veterinary medicine. The manuscript management system is completely online and includes a very quick and fair peer-review system.

Submit your manuscript here: http://www.dovepress.com/veterinary-medicine-research-and-reports-journal 